\title{
Evaluation of Low-dose Multi-slice CT Scanning in Children Chest Examination
}

\author{
Guohua $\mathrm{Li}^{1, \mathrm{a}}$, Weilin Tang ${ }^{1, \mathrm{~b}}$ and Shengjian Sun ${ }^{1, \mathrm{c}}$ \\ ${ }^{1}$ Department of Radiology, the First Affiliated Hospital of Qiqihar Medical University Qiqihar, China \\ aliguohua141203@126.com, ²gaojianhua0901@126.com, 'ddliok@sina.com
}

Keywords: Radiation dose; Children patients; Computed tomography; X-ray computer; Peripheral hemogram; Radiation effect

\begin{abstract}
Objective: To evaluate the application effect and value of low-dose $\mathrm{kV}$ and $\mathrm{mA}$ for chest examination in children by multi-slice CT.

Methods: 120 children underwent chest CT were enrolled and divided into six groups according to different $\mathrm{kV}$ and $\mathrm{mA}$ values. Average CT dose index (CTDIvol, $\mathrm{mGy}$ ) and dose length product $\left(\mathrm{DLP}, \mathrm{mGy}^{*} \mathrm{~cm}\right)$ in each group were recorded. Effective dose (ED, $\left.\mathrm{mSV}\right)$ was calculated by DLP, $\mathrm{ED}=\mathrm{k} \times \mathrm{DLP}[\mathrm{k}$ value $=0.039]$. Image quality analysis was independently conducted by two experienced doctors. Radiation dose and image quality were compared among six groups. Peripheral blood cells of each child were respectively detected before and after test ( 2 hours, 1 day, 1 week and 4 weeks).

Results: Radiation doses in each group (CTDIvol, DLP and ED) were decreased to the control group, in which the combined reduction group dropped approximately 50\%. There was no significant difference in image quality among each group and all meet the diagnostic requirements. No significant change was observed in peripheral blood cell counts of children before and after test.

Conclusions: Low-dose multi-slice CT scanning for chest examination combined reduction of $\mathrm{kV}$ and $\mathrm{mA}$ value may effectively reduce hazards of radiation to children, with the image quality meeting the diagnostic requirements.
\end{abstract}

\section{Introduction}

So far, multi-slice CT has been widely used for children in chest examination, which has the advantages of fast scan speed and high-resolution image. But the side effects of higher radiation doses have aroused more and more attention [1]. Children are in growth and development stages and are more sensitive to radioactive rays than adults, so radiation doses should be reduced during CT examination [2]. International and domestic academics have done a series of researches and assessments [3], however, there is few research about the clinical effect and application value of using low-dose multi-slice CT scanning in children chest examination. This study aimed to study the clinical effect and application value of using low-dose multi-slice CT scanning in children chest examination combined reduction of $\mathrm{kV}$ and $\mathrm{mA}$ value, hoping to provide a safer, less invasive and more reliable way to perform clinical examination.

\section{Materials and Methods}

General Information. 120 children patients (58 males and 62 females, aged 2 13 years, mean age $7.33 \pm 3.02$ years) underwent chest computed tomography (CT) in the period between June 2012 and March 2014 in our hospital. All children patients were divided into six groups $(20$ samples in each group) according to different $\mathrm{kV}$ (X-ray tube voltage) and $\mathrm{mA}$ (X-ray tube current) values, including control group, $100 \mathrm{kV}$ group, $80 \mathrm{kV}$ group, $80 \mathrm{~mA}$ group, $60 \mathrm{~mA}$ group and combined reduction group. There was no statistically significant difference in age, gender and general pathogenic condition.

Experiment Method. The patient lied on the scanning bed while the 64-slice spiral CT (Aquilion, Toshiba) scanned from rib cage to diaphragm. Injection of a 10\% solution of chloral 
hydrate was recommended when children could not hold breath to cooperate with the doctor. Firstly, we performed a topogram scan, then prepared the specific scanning program. Parameters for topogram scan were: filter function (L03), $120 \mathrm{kV}, 100 \mathrm{~mA}$; parameters for scanning and reconstruction were: spiral scan, D-FOV (L field, 400mm); specific scanning parameters were: control group $(120 \mathrm{kV}, 100 \mathrm{~mA}), 100 \mathrm{kV}$ group $(100 \mathrm{kV}, 100 \mathrm{~mA}), 80 \mathrm{kV}$ group $(80 \mathrm{kV}, 100 \mathrm{~mA})$, $80 \mathrm{~mA}$ group $(120 \mathrm{kV}, 80 \mathrm{~mA}), 60 \mathrm{~mA}$ group $(120 \mathrm{kV}, 60 \mathrm{~mA})$ and combined reduction group $(100 \mathrm{kV}, 60 \mathrm{~mA})$. Other scanning parameters were consistent, including layer thickness $8.0 \mathrm{~mm}$, reconstruction thickness $1.5 \mathrm{~mm}$, pitch 0.98 , matrix $512 \times 512$. Lead clothes were used to protect sensitive tissues during scanning, such as thyroid, breast and gonads. After scanning, images were uploaded to Syngo workstation to perform image analysis and post-processing.

Radiation Dose and Image Quality. Parameters of radiation dose automatically generated according to the scanning parameter settings (tube current: $\mathrm{mA}$, tube voltage: $\mathrm{kV}$ and pitch), recorded average computed tomography dose index (CTDIvol, mGy) and dose-length product (DLP, $\left.m G{ }^{*} \mathrm{~cm}\right)$ in ench group. Effective dose $(\mathrm{ED}, \mathrm{mSV})$ was calculated by DLP, ED=k $\times$ DLP $[\mathrm{k}$ value $=0.039$ [4], recommended by the European Commission]. The standard deviation of CT value was regarded as the noise value. Image quality analysis was independently conducted by two experienced doctors. The results were divided into three levels. Excellent level: lung tissue, mediastinum and trachea-bronchia were clearly displayed which had no obvious artifacts, and could meet requirements to the diagnosis. Good level: lung tissue, mediastinum and trachea-bronchia could be seen which existed a small amount of artifacts, and did not influence the diagnostic accuracy. Poor level: lung tissue, mediastinum and trachea-bronchia could not accurately display which was hard to distinguish where normal tissue structures, and did not meet the diagnostic requirements. The number and the percentage of image quality from different levels were recorded.

Analysis of Peripheral Blood Cells. Peripheral blood cells of each children patients were respectively detected before and after test ( 2 hours, 1 day, 1 week and 4 weeks). We obtained $1 \mathrm{ml}$ venous blood sample and collected in glass tubes with EDTA-K $\mathrm{K}_{2}$, and then tested several indicators, including white blood cell, lymphocyte, intermediate cell, granulocyte, red blood cell, hemoglobin, hematocrit and platelet.

Statistic Analysis. Statistical analysis was performed by SPSS 18.0 software. All the measurement data were in the form of $($ mean $\pm \mathrm{sd})$. The comparison of radiation doses from different groups were analyzed by Paired Student's t test, which was also used in the comparison of peripheral blood cells. $\mathrm{P}<0.05$ indicated a statistically significant difference.

\section{Results}

Comparison of Radiation Doses. Radiation doses in each group (CTDIvol, DLP and ED) were shown in Table 1. Values of CTDIvol, DLP and ED in the combined reduction group dropped approximately $50 \%$ than the control group. 
Table 1 Comparison of radiation doses (ctdivol, dlp and ed) in each group ( $\bar{x} \pm s$ )

\begin{tabular}{|c|c|c|c|}
\hline $\begin{array}{c}\text { Group } \\
\text { Type }\end{array}$ & $\begin{array}{c}\text { CTDIvol } \\
(\mathbf{m G y})\end{array}$ & $\begin{array}{c}\text { DLP } \\
(\mathbf{m G y} \mathbf{c m})\end{array}$ & ED $(\mathbf{m S v})$ \\
\hline $\begin{array}{c}\text { Control } \\
\text { group }\end{array}$ & $18.69 \pm 3.2$ & $102.56 \pm 4.6$ & $3.99 \pm 2.1$ \\
\hline $\begin{array}{c}100 \mathrm{kV} \\
\text { group }\end{array}$ & $14.01 \pm 2.1^{*}$ & $87.18 \pm 5.1^{*}$ & $3.4 \pm 1.4^{*}$ \\
\hline $\begin{array}{c}80 \mathrm{kV} \\
\text { group }\end{array}$ & $10.12 \pm 3.9^{*}$ & $76.92 \pm 1.8^{*}$ & $2.9 \pm 2.9^{*}$ \\
\hline $\begin{array}{c}80 \mathrm{~mA} \\
\text { group }\end{array}$ & $14.95 \pm 4.1^{*}$ & $82.05 \pm 3.2^{*}$ & $3.2 \pm 3.1^{*}$ \\
\hline $\begin{array}{c}60 \mathrm{~mA} \\
\text { group }\end{array}$ & $8.97 \pm 5.1^{*}$ & $61.54 \pm 2.7^{*}$ & $2.4 \pm 1.7 *$ \\
\hline $\begin{array}{c}\text { Combined } \\
\text { reduction } \\
\text { group }\end{array}$ & $7.18 \pm 1.9^{*}$ & $51.28 \pm 2.5^{*}$ & $1.9 \pm 3.1^{*}$ \\
\hline
\end{tabular}

*: compared with control group, $\mathrm{P}<0.05$

Comparison of Image Quality. There was no significant difference in image quality among each group and all of them could meet the diagnostic requirements (Table 2).

Table 2 Comparison of image quality in each group (percentage, case number)

\begin{tabular}{|c|c|c|c|}
\hline Group Type & Excellent & Good & Poor \\
\hline Control group & $\begin{array}{c}90 \% \\
(18 / 20)\end{array}$ & $10 \%(2 / 20)$ & $0 \% \quad(0 / 20)$ \\
\hline $100 \mathrm{kV}$ group & $\begin{array}{c}80 \% \\
(16 / 20)\end{array}$ & $15 \%(3 / 20)$ & $5 \%(1 / 20)$ \\
\hline $80 \mathrm{kV}$ group & $\begin{array}{c}75 \% \\
(15 / 20)\end{array}$ & $20 \%(4 / 20)$ & $5 \%(1 / 20)$ \\
\hline $80 \mathrm{~mA}$ group & $\begin{array}{c}90 \% \\
(18 / 20)\end{array}$ & $5 \%(1 / 20)$ & $5 \%(1 / 20)$ \\
\hline $60 \mathrm{~mA}$ group & $\begin{array}{c}70 \% \\
(14 / 20)\end{array}$ & $20 \%(4 / 20)$ & $10 \%(2 / 20)$ \\
\hline $\begin{array}{l}\text { Combined } \\
\text { reduction } \\
\text { group }\end{array}$ & $\begin{array}{c}70 \% \\
(14 / 20)\end{array}$ & $15 \%(3 / 20)$ & $15 \%(3 / 20)$ \\
\hline$\chi 2$ value & 1.803 & 2.706 & 1.386 \\
\hline$P$ value & $>0.05$ & $>0.05$ & $>0.05$ \\
\hline
\end{tabular}

Comparison of Peripheral Blood Cell Counts. There was no significant difference between before test and after test ( 2 hours, 1 day, 1 week and 4 weeks) in peripheral blood cell counts of children patients (Table 3 ).

Table 3 Comparison of peripheral blood cell counts before and after test ( $\bar{x} \pm s$ )

\begin{tabular}{|c|c|c|c|c|c|}
\hline Haemocyte & Before test & 2 hours & 1 day & 1 week & 4 weeks \\
\hline WBC $(\times 109 / \mathrm{L})$ & $6.12 \pm 1.49$ & $6.58 \pm 1.87^{*}$ & $5.89 \pm 0.61^{*}$ & $6.21 \pm 0.89^{*}$ & $5.97 \pm 0.33^{*}$ \\
\hline Lymph $(\times 109 / \mathrm{L})$ & $3.12 \pm 0.91$ & $2.99 \pm 1.61^{*}$ & $3.09 \pm 1.67^{*}$ & $3.04 \pm 1.44^{*}$ & $2.85 \pm 1.25^{*}$ \\
\hline Mid $(\times 109 / \mathrm{L})$ & $0.59 \pm 1.07$ & $0.62 \pm 1.21^{*}$ & $0.60 \pm 1.33^{*}$ & $0.63 \pm 0.05^{*}$ & $0.63 \pm 1.08^{*}$ \\
\hline Gram $(\times 109 / \mathrm{L})$ & $4.03 \pm 2.34$ & $3.98 \pm 1.56^{*}$ & $4.10 \pm 1.07^{*}$ & $4.27 \pm 1.94^{*}$ & $3.87 \pm 1.36^{*}$ \\
\hline RBC $(\times 109 / \mathrm{L})$ & $5.19 \pm 1.19$ & $6.28 \pm 0.84^{*}$ & $6.02 \pm 1.06^{*}$ & $5.34 \pm 0.66^{*}$ & $6.05 \pm 0.99^{*}$ \\
\hline Hb (g/L) & $148.32 \pm 10.48$ & $139.02 \pm 12.37^{*}$ & $142.01 \pm 11.65^{*}$ & $142.36 \pm 9.07^{*}$ & $141.02 \pm 9.11^{*}$ \\
\hline HCT $(\%)$ & $45.16 \pm 3.28$ & $46.09 \pm 2.37^{*}$ & $47.01 \pm 2.38^{*}$ & $46.16 \pm 3.28^{*}$ & $47.01 \pm 2.78^{*}$ \\
\hline PLT $(\times 109 / \mathrm{L})$ & $181.35 \pm 35.19$ & $182.65 \pm 29.09^{*}$ & $189.55 \pm 28.09^{*}$ & $179.25 \pm 28.36^{*}$ & $190.05 \pm 28.55^{*}$ \\
\hline
\end{tabular}




\section{Discussions}

Multi-slice spiral CT have the advantage of speeding the CT examination, getting higher imagine resolution and time resolution, and the acquisition of a volume dataset enables us to perform three dimensional reconstruction, curved planar reconstruction in post-processing workstation, which have greatly improved the accuracy of CT diagnosis [5]. However, medical X-ray radiation has become the largest source of unnatural radiation and excess X-ray radiation would cause permanent damage of human chromosome. Children are in growth and development stages and are more sensitive to radioactive rays than adults [6]. So it is necessary to be extra careful to carry on a CT examination for children, complying with the principle of "as low as reasonably achievable" (ALARA) [7] to reduce radiation dose to a minimum recording on the basis of guaranteeing image quality.

Main approaches for reducing radiation dose include reducing $\mathrm{kV}$ value, reducing $\mathrm{mA}$ value, using the technology of automatic tube current, expanding pitches and the application of special image reconstruction methods [8]. The technology of automatic tube current could reduce hazards of radiation, but it require hardware support [9]. Special image reconstruction methods include adaptive statistical iterative reconstruction (ASIR) from GE company, iterative reconstruction in image space (IRIS) and sonogram affirmed iterative reconstruction (SAFIRE) from Siemens company and dual model iterative reconstruction method (iDose) from Philips company. All these reconstruction methods need specific support of hardware and software. Reduction of radiation dose certainly will influence the image quality, increase the image noise and then reduce the spatial resolution. Lung is mainly composed of gas organization, and have the feature of nature high contrast. Children accept lower X-ray radiation dose than adults on account of small lung volume, so increased noisy signal will not influence the image quality [10]. It is a simple and useful way to reduce radiation dose by reducing $\mathrm{kV}$ value or $\mathrm{mA}$ value which had been used a lot in previous studies. Our study reduced $\mathrm{kV}$ value and $\mathrm{mA}$ value together to further reduce radiation dose and meet the diagnostic requirements. Decreased radiation dose shows exponential decline with $\mathrm{kV}$ value, which lead to the number of photons decrease when they reach human tissues, with the increasing of image noise ${ }^{[11]}$. In chest CT images, decreased image quality has no effect

In chest CT images, decreased image quality has no effect on diagnosing by increasing of image noise, but which could significantly reduce radiation dose. In our study, both $100 \mathrm{kV}$ group and 80 $\mathrm{kV}$ group showed no significant difference with control group in image quality. It exists a linear relationship between reduced $\mathrm{mA}$ value and decreased radiation dose, which has a bad influence on images in degrading the spatial resolution [12]. Our study chose $\mathrm{mA}$ value that could reduce chest CT scanning. The length of scanning in children was shorter than adults because of the smaller chest area of children, so the scanning time and exposure time both became shorter, which could further reduce radiation dose. Researches showed that exposure to radiation for a long time could influence peripheral blood cell counts, especially reduction of leukocyte had inhibition to medullary hematopoiesis function. Radiation exposure in children could be effectively reduced by regulating the scanning program for children chest CT examination. And there was no significant difference between before test and after test ( 2 hours, 1 day, 1 week and 4 weeks) in peripheral blood cell counts of children patients.

In chest $\mathrm{CT}$ images, decreased image quality has no effect on diagnosing by increasing of image noise, but which could significantly reduce radiation dose. In our study, both $100 \mathrm{kV}$ group and 80 $\mathrm{kV}$ group showed no significant difference with control group in image quality. It exists a linear relationship between reduced $\mathrm{mA}$ value and decreased radiation dose, which has a bad influence on images in degrading the spatial resolution [12]. Our study chose mA value that could reduce chest CT scanning. The length of scanning in children was shorter than adults because of the smaller chest area of children, so the scanning time and exposure time both became shorter, which could further reduce radiation dose. Researches showed that exposure to radiation for a long time could influence peripheral blood cell counts, especially reduction of leukocyte had inhibition to medullary hematopoiesis function. Radiation exposure in children could be effectively reduced by regulating the scanning program for children chest CT examination. And there was no significant difference 
between before test and after test ( 2 hours, 1 day, 1 week and 4 weeks) in peripheral blood cell counts of children patients.

\section{Conclusions}

Low-dose multi-slice CT scanning for chest examination combined reduction of $\mathrm{kV}$ and $\mathrm{mA}$ value may effectively reduce hazards of radiation to children and the image quality meet the diagnostic requirements and is worth of being generalized.

\section{References}

[1] Kirpalani H, Nahmias C. Radiation risk to children from computed tomography. Pediatrics. 2008, 121(2): 449-450.

[2] Sigurdson pU, Ronckers cM, Mertens Ac, et a1. Primary thyroid cancer after a first tumour in childhood(the Childhood Cancer Survivor Study): A nested case•control study. Lancet, 2005, 365(9476): 2014-2023.

[3] Yang CY, Chen YF, Lee CW, et a1. Multiphase CT angiography versus single-phase CT angiography: comparison of image quality and radiation dose. Am J Neuroradiol。2008, 29(7): 1288-1295.

[4] Mc Collough CH, Primak AN, Braun N, et a1. Strategies for reducing radiation dose in CT. Radiol Clin North Am, 2009, 47(1): 27-40.

[5] Yamamura, J., et al., Simulated Low-Dose Computed Tomography in Oncological Patients: A Feasibility Study. Journal Of Computer Assisted Tomography, 2010. 34(2): p. 302-308.

[6] Hein, P.A., et al., Computer-Aided Pulmonary Nodule Detection - Performance of Two CAD Systems at Different CT Dose Levels. Rofo-Fortschritte Auf Dem Gebiet Der Rontgenstrahlen Und Der Bildgebenden Verfahren, 2009. 181(11): p. 1056-1064.

[7] Yamamura, J., et al., Dose Reduction in High-Resolution MSCT Examinations of the Chest for Early Detection of Pneumonia in Immunocompromised Patients. Rofo-Fortschritte Auf Dem Gebiet Der Rontgenstrahlen Und Der Bildgebenden Verfahren, 2009. 181(6): p. 549-555

[8] Hein, P.A., et al., Linear and Volume Measurements of Pulmonary Nodules at Different CT Dose Levels - Intrascan and Interscan Analysis. Rofo-Fortschritte Auf Dem Gebiet Der Rontgenstrahlen Und Der Bildgebenden Verfahren, 2009. 181(1): p. 24-31.

[9] Das, M., et al., Accuracy of automated volumetry of pulmonary nodules across different multislice CT scanners. European Radiology, 2007. 17(8): p. 1979-1984.

[10] Hohl, C., et al., Estimation of radiation exposure in low-dose multislice computed tomography of the heart and comparison with a calculation program. European Radiology, 2006. 16(8): p. $1841-1846$.

[11] Schafer, J.F., et al., Detection of pulmonary nodules with breath-hold magnetic resonance imaging in comparison with computed tomography. Rofo-Fortschritte Auf Dem Gebiet Der Rontgenstrahlen Und Der Bildgebenden Verfahren, 2005. 177(1): p. 41-49.

[12]Fraioli, F., et al., Evaluation of effectiveness of a computer system (CAD) in the identification of lung nodules with low-dose MSCT: scanning technique and preliminary results. Radiologia Medica, 2005. 109(1-2): p. 40-48. 